\title{
A reorganização das elites diante da desorganização do sistema latifúndio/moradia no Cariri Ocidental da Paraíba
}

\author{
Kátia Carina Mesquita Cruz de Araújo ${ }^{1}$
}

\begin{abstract}
Resumo: O presente estudo é parte da pesquisa realizada no Mestrado em Ciências Sociais da UFCG, tendo por objetivo analisar as relações entre a posse da terra e sua função social, econômica e política, estabelecendo relações com o fenômeno da perpetuação do poder local das históricas famílias políticas no Estado da Paraíba, tomando como objeto privilegiado a família Gaudêncio na cidade de Serra Branca/PB. Buscou-se, assim, responder como as famílias políticas tradicionais utilizam-se do capital econômico e das estruturas do latifúndio para processos de arregimentamento eleitoral? Com base nesta questão-problema, e utilizando-me da metodologia qualitativa, entrevista semiestruturada e trabalho de campo, constatou-se que as famílias tradicionais exerceram forte influência no sistema latifundiário-moradia. E que os impactos nesse sistema e modo de vida também alteraram a configuração e as relações de poder na dinâmica da política local.
\end{abstract}

Palavras-chave: Elites locais. Poder político. Desorganização do sistema latifúndio/moradia.

\section{The reorganization of the elites in the face of the disorganization of the latifundio / dwelling system in the Western Cariri of Paraíba.}

\begin{abstract}
The present study is part of the research carried out in the Master in Social Sciences of the UFCG, aiming to analyze the relations between land tenure and its social, economic and political function, establishing relations with the phenomenon of the perpetuation of local power of the historical Political families in the State of Paraíba, taking as a privileged object the Gaudêncio family in the city of Serra Branca / PB. It was sought, therefore, to answer how the traditional political families use of the economic capital and the structures of the latifundio for processes of regrouping electoral? Based on this problem question, and using qualitative methodology, semi-structured interview and fieldwork, it was verified that traditional families exerted a strong influence on the latifundio-dwelling system. And that the impacts on this system and way of life have also altered the configuration and power relations in the dynamics of local politics.
\end{abstract}

Keywords: Local elites. Political power. Disorganization of the latifundia / housing system.

- Enviado em 01/05/2017

- Aprovado em 17/05/2017

\footnotetext{
${ }^{1}$ Kátia Carina Mesquita Cruz de Araújo. Graduad@ em Ciências Sociais pela Universidade Federal de Campina Grande. Especialista em Educação Contextualizada para a Convivência com o Semiárido Brasileiro pela Universidade Federal de Campina Grande. Especialista em Educação e Práticas Interdisciplinares de Ensino pela Universidade Estadual da Paraíba. Mestre em Ciências Sociais pela Universidade Federal de Campina Grande. Professora na Universidade Federal de Campina Grande no Centro de Desenvolvimento Sustentável do Semiárido - CDSA. < http://lattes.cnpq.br/9810382232847717. Uma versão preliminar desse texto foi apresentada no VIII Seminário Nacional de Sociologia e Política realizado de 17 a 19 de maio de 2017 na UFPR. E-mail: kcmcruz@yahoo.com.br
} 


\section{INTRODUÇÃO}

O presente estudo ora apresentado teve por objetivo analisar as transformações no fazer político da família Gaudêncio, no Cariri Ocidental da Paraíba e, mais particularmente, no município de Serra Branca, num quadro de mudanças provocadas pela crise do sistema latifúndio/moradia. A decadência do latifúndio, que não deve ser confundida com o desaparecimento da grande propriedade, pode ser associada com a perda de poder político, nos níveis nacional e estadual, a partir da década de 1980. Neste período, o desempenho eleitoral de representantes da família Gaudêncio em pleitos regionais foi se deteriorando, ainda que o grupo político tenha conseguido manter sua predominância no nível local, mesmo tendo enfrentado alguns revezes eleitorais. A pesquisa revela as maneiras pelas quais os próprios membros da família Gaudêncio narram às transformações no contexto local e como elaboram, nestas narrativas, explicações para as permanências e mudanças no fazer político, que permitem a continuidade de um tipo de poder local dominando pelas famílias tradicionais. Buscou-se, assim, responder como as famílias políticas tradicionais utilizam-se do capital econômico e das estruturas do latifúndio para processos de arregimentamento eleitoral? Com base nesta questão-problema, e utilizando-me da metodologia qualitativa, entrevista semiestruturada e trabalho de campo, constatou-se que as famílias tradicionais exerceram forte influência no sistema latifundiário-moradia. E que os impactos nesse sistema e modo de vida também alteraram a configuração e as relações de poder na dinâmica da política local.

Em um contexto histórico a propriedade da terra foi alvo de inúmeras disputas de caráter desigual, tendo como uma de suas marcas a segregação social em nosso território, onde os grupos oligárquicos tinham acesso diferenciado e prioritário à doação de grandes extensões de terra. Conforme Faoro (2004, p.407), para se chegar ao acesso a terra era necessário prestígio político, pois não se podia confiar a terra ao vaqueiro, ao lavrador. A propriedade seria desta sorte, uma afirmação aristocrática, para uma grande empresa ou para o domínio de lavradores e vaqueiros. Dessa forma, a propriedade agrária brasileira se concentrou, desde os remotos tempos da colonização, em torno da grande propriedade privada, aumentando cada vez mais a dificuldade do 
camponês em deter um pedaço de terra para si, onde pudesse trabalhar e produzir o sustento da família.

Neste trabalho, tentou-se compreender o processo que ora denominou-se de crise do sistema latifúndio/moradia ${ }^{2}$, processo este que se intensifica conforme Moreira (1997) a partir da década de 1970 com a crise da economia canavieira; a crise nas lavouras de algodão causadas com a praga do bicudo; as migrações sazonais; as mudanças nas relações de trabalho no campo e o surgimento dos movimentos sociais dentre outros.

A pesquisa tomou como objeto privilegiado de investigação a trajetória agrária e política da família Gaudêncio na cidade de Serra Branca a partir da década de 1970 e às mudanças em seu fazer político. Ou seja, buscou-se apreender como as mudanças na estrutura fundiária e nas formas de organização social relacionadas à grande propriedade ocorridas a partir das décadas de 1970 e 1980 repercutem no poder local em Serra Branca (PB) atualmente. Acreditou-se ser possível compreender como a família Gaudêncio, em especial, elabora, vivencia, justifica e cria novas estratégias a partir das mudanças com as quais seus membros têm que lidar. Neste processo, a hipótese de pesquisa foi a de que os membros da família Gaudêncio reinventam o próprio fazer político, criando novas maneiras pelas quais se vinculam elite local e população/eleitores e nesse contexto essa reinvenção não é um processo estático, mais um "algo" constante no sentido de ser uma reorganização de suas estratégias e seu modo de fazer político.

\section{A FAMÍLIA GAUDÊNCIO EM SERRA BRANCA}

A cidade de Serra Branca está localizada no Cariri Ocidental da Paraíba, tem uma área de $804 \mathrm{Km}^{2}$, distante $240 \mathrm{~km}$ da capital do estado - João Pessoa, e conta atualmente com uma população de 13.637 habitantes (IBGE 2016). Como em toda a região do semiárido brasileiro,

\footnotetext{
${ }^{2}$ Processo ocorrido com as transformações na estrutura agrária, após a crise do sistema pecuária/algodão/sisal/culturas alimentares/moradia/latifúndio, mudança nas relações de trabalho, avanço da pecuária em relação a lavouras temporárias, mudanças na política de trabalho assalariado com relação ao sistema de moradia.
} 
Serra Branca reúne um conjunto de características climáticas, geomorfológicas, econômicas e sociais peculiares que resultam numa paisagem marcada pela dificuldade no acesso a recursos hídricos e pela resistência de sua população. Do ponto de vista climático, Serra Branca é marcada pela forte insolação, pela baixa nebulosidade, por elevadas taxas de evaporação, por temperaturas constantes e relativamente altas, pelo regime de chuvas definido pela irregularidade e concentração das precipitações num curto período de tempo.

\section{MAPA 1 - LOCALIZAÇÃO GEOGRÁFICA DO CARIRIPARAIBANO}

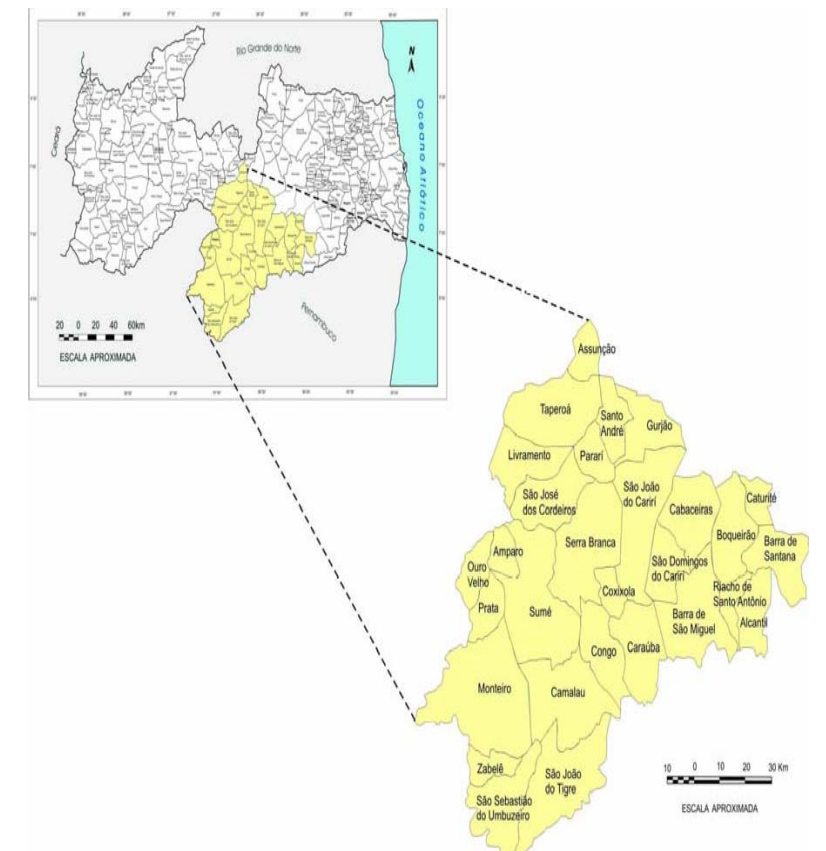

Fonte : Anieres Barbosa da Silva (2003), a partir de PARAÍBA. IDEME, 2000.

Como na maioria das cidades da Paraíba, em Serra Branca, o poder local foi fortemente marcado pelas relações de mando associado às grandes propriedades rurais que como em todo Cariri se destacavam pelo cultivo e venda do algodão. Pois, conforme Gurjão (1994, p. 20-21) nas fazendas de gado do Cariri, responsáveis pela estruturação inicial desses espaços havia se instituído relações de produção diversificadas e uma divisão interna do trabalho que se adequaram à produção algodoeira. Nessas áreas, o cultivo de algodão facilmente expandiu-se favorecido pelo baixo custo de sua cultura, na medida em que requeria pouco investimento de 
capital, complementava a atividade pecuária, uma vez que o restolho da lavoura servia de alimento para o gado, além de adequar-se ao trabalho de "moradores", "meeiros", assalariados e pequenos proprietários. O algodão também se adaptou ao esquema de trocas já montado nas áreas agropastoris, dinamizando-o, já que as tropas de burros que conduziam couros, peles e produtos da lavoura de subsistência às feiras, passaram a comercializar também o algodão.

A história da família Gaudêncio confunde-se com a própria história de Serra Branca, uma vez que o destino do município esteve por muitas décadas de forma direta nas mãos deste grupo familiar e político, que embora não se reconheça ${ }^{3}$ como grande proprietária de terra, e negue que o seu poder político tenha relação com a posse e o usufruto das fazendas, é dona de várias propriedades da região no entorno de Serra Branca. Neste sentido, o capital social pode ser entendido como "conjunto de recursos, efetivos ou potenciais, relacionados com a posse de uma rede durável de relações, mais ou menos institucionalizadas, de interconhecimento e de reconhecimento" (BOURDIEU, 1980). O capital social, portanto, depende da extensão da rede de ligações que ele pode mobilizar e do volume de capital (econômico, cultural ou simbólico) possuído por cada um daqueles a quem ele está ligado.

Ressalta-se que em uma região de longas estiagens como o semiárido - destaca-se aqui o Cariri Paraibano e, em especial, Serra Branca, a água concentrada permitia maior controle sobre os trabalhadores rurais e de forma mais ampla de boa parte da população. Estes dependiam desses bens para sobreviver, para suprir suas necessidades básicas e materiais de existência. Como a terra era então o principal meio de produção, os trabalhadores rurais supriam suas necessidades materiais trabalhando nas terras dos latifundiários. Assim, cria-se a necessidade de mão de obra assegurada pela força de trabalho dos moradores, meeiros e pequenos sitiantes (GURJÃO, 1994). Esse processo, induzido pelo Estado brasileiro, através da implantação de benfeitorias nas grandes propriedades, por meio de financiamentos, constituiu-se material e simbolicamente em força e poder político dos "coronéis" da oligarquia algodoeira/pecuária, como no caso da família Gaudêncio.

Coincidentemente, com as mudanças nas relações do sistema latifúndio/moradia, ocorrido a partir da década de 1970 e 1980 como a crise do sistema de moradia e o avanço do trabalho

\footnotetext{
${ }^{3}$ Através das entrevistas realizadas com membros da família Gaudêncio, os mesmos não associam o prestigio social e político da família à sua relação com a terra.
} 
assalariado, bem como a política de distribuição de terras a exemplo da reforma agrária e de outras mudanças significativas nas transformações de produção no campo, o poder da família Gaudêncio sofre forte abalo diante das próprias formas de fazer políticas.

\section{O LATIFÚNDIO COMO MODO DE ORGANIZAÇÃO SOCIAL E DE PRODUÇÃO NO PROCESSO DE POVOAMENTO DO CARIRI OCIDENTAL DA PARAÍBA}

De acordo com Houaiss (2001), o termo latifúndio (do latim latifundium,ĭi)refere-se à: 1) "entre os antigos romanos, grande propriedade rural pertencente à aristocracia, na qual, à custa da força do trabalho escravo, praticava-se o cultivo da oliva, da vinha e a criação de animais" e 2. "vasto domínio rural constituído de terras não cultivadas e/ou de áreas onde se pratica um tipo de cultura que não exige grandes investimentos". Nas duas acepções, e de modo diverso de muitas utilizações contemporâneas do termo, o latifúndio se define tanto pelo tamanho da propriedade como por um modo de produzir na terra. Se por um lado, entre os romanos, o termo latifundiário denominava o uso do trabalho escravo no cultivo da oliva, da vinha e na criação de animais, na acepção mais geral, significa um modo de produção não capitalista.

No semiárido brasileiro, o tipo de latifúndio mais encontrado alude às extensões de terra cuja produção é feita sob modos de cultivo de baixo investimento. No caso do Cariri Ocidental da Paraíba e, em especial na cidade de Serra Branca, o predomínio é da cotonicultura que, juntamente com o gado e a policultura alimentar, tornou-se a base da economia da região, sendo estas culturas responsáveis em grande parte pelo processo de povoamento do interior paraibano e, de forma mais determinante, do povoamento do Cariri Ocidental.

Neste contexto buscou-se analisar em quais contextos foram intensificados o processo de povoação da região do Cariri e as relações sociais que foram estabelecidas no entorno da posse da terra, uma vez que o latifúndio não está demarcado apenas pela posse da terra e de sua extensão, mas também por todo um modo de vida dos atores sociais envolvidos e suas relações mais intensificadas por questões sociais, tais como: patriarcado; clientelismo; relações entre o morador 
da terra e o proprietário; às relações de trabalho estabelecida como a figura do vaqueiro, responsável por cuidar do rebanho com base no regime de quarteação; à presença de parceiros e arrendatários; etc.

Nesse viés de raciocínio, foi necessário refletir sobre a influência que esse processo de povoamento teve na consolidação de um grupo político, representado nesse contexto pela família Gaudêncio, família esta advinda de uma elite agrária e que usou o poder da terra para traçar a vida política naquela região, mais especificamente em Serra Branca, e permanecer no cenário político do Estado da Paraíba.

Por ter sido este território a parte da colônia portuguesa onde se implantaram inicialmente monoculturas de cana-de-açúcar e, posteriormente de fumo, algodão e pastagens, essa região propiciou uma maior concentração de terras nas mãos de poucas pessoas e um maior enraizamento do latifúndio que acabou por impedir uma melhor repartição da terra. Todas essas relações foram responsáveis por uma forte desigualdade de classes sociais, subordinada em sua grande maioria aos interesses do capital financeiro e industrial, e que não atendia a maioria das necessidades da população.

Consoante Junior e Bursztyn (2008), no Nordeste a margem foi subsidiada ao latifúndio açucareiro, e no sertão desenvolveu-se a pecuária e a agricultura de subsistência. Já Moreira e Targino (1997, p.68), apontam que o boi originalmente fixado nas terras litorâneas, para apoiar as atividades do engenho, foi levado para o interior sempre seguindo o curso dos rios, formando os chamados caminhos do gado, originando os currais, as feiras de gado e, consequentemente, 0 aparecimento dos povoados e vilas que depois se tornam cidades, tais como: Boqueirão, Cabaceiras, Piancó, Vila Rainha (hoje Campina Grande), Itabaiana, Pombal, Sousa, Patos, Cajazeiras, Princesa Isabel, e muitas outras cidades e povoados que foram se formando em função dos percursos econômicos desenvolvidos nos sertões da Paraíba.

Junior e Bursztyn (2008) pontuam que com o decorrer do tempo houve uma decadência do nordeste açucareiro, e na mesma intensidade na Paraíba, aconteceu um decréscimo da função dessa economia pastoril e, por conseguinte, uma dispersão das terras dos currais. O que propiciou o desenvolvimento de uma nova forma camponesa e coletiva de uso da terra, agora com a cultura do algodão no Sertão e Cariri da Paraíba. 
A região do Cariri, em especial na sua formação, sofreu a forte influência do cultivo do algodão, ou seja, a cotonicultura que, juntamente com o gado e a policultura alimentar, tornou-se a base da economia do Cariri. Esta cultura impulsionada por condições externas favoráveis (crescimento da demanda provocada pelo desenvolvimento da indústria têxtil inglesa) estendeuse rapidamente tanto nas áreas de Caatinga quanto no Brejo e até mesmo no Litoral, aonde chegou a concorrer com a cana-de-açúcar. A expansão do algodão no Agreste paraibano provocou profundas modificações neste espaço em gestação. Os seus reflexos fizeram-se sentir tanto na organização agrária como no quadro urbano regional.

Ademais, a demanda pelo algodão por parte dos países industrializados representou uma nova fonte de renda para os produtores que se dedicavam unicamente a pecuária e fez emergir internamente uma agricultura comercial que aos poucos foi sendo direcionada, sobretudo para o mercado externo, especialmente para atender as necessidades da indústria têxtil inglesa, que apresentava elevado progresso tecnológico.

Conforme Moreira e Targino (1997), no decorrer do tempo, intensificou-se o número de pessoas que arrendaram, subarrendaram ou passaram a solicitar a posse de vastas extensões de terras, nas quais diziam ter efetivado plantações e construído currais, emergindo, assim, novos grupos familiares que passaram a deter tanto o poder político quanto o econômico, com base na concentração de terras.

Diante disso, um dos traços marcantes na posse da terra nessa região era o fato de que os grandes proprietários que ali se instalaram dispunham de poder absoluto nos limites de suas propriedades. Esses grandes proprietários segundo Maia (2013, p.42), utilizavam-se desse poder econômico e social para coibir aqueles que Ihes deviam favores, dispondo e explorando assim da mão-de-obra de que necessitam.

Esses atores controlavam o poder local, através da política do clientelismo, onde o patrão dava proteção ao outro em troca de apoio, estabelecendo um laço de submissão pessoal, independente das relações de parentesco, de emprego, ou de métodos violentos. Através dessas relações de poder, os grandes proprietários mantinham ainda articulações políticas com o governo federal e com os governos estaduais, visto que exerciam forte influência sobre as camadas mais pobres da sociedade por exigir fidelidade em troca de favores. Assim, por meio do medo e da subserviência, dominavam verdadeiros "currais" eleitorais, tendo em vista que o voto era aberto e 
quem ousasse discordar da orientação política era severamente punido. Surge assim a figura do Coronel ${ }^{4}$.

Dentre os grupos familiares, que passaram a atuar na região em estudo, está à família Gaudêncio que primeiramente se instalou em São João do Cariri e com a emancipação política do distrito de Serra Branca torna-se uma das famílias fundadoras da cidade, visto ser a maior proprietária das terras da região, detentora do monopólio do cultivo e da venda do algodão. Entretanto, com as mudanças existentes no sistema latifúndio/moradia, conforme mencionado acima e debater-se-á mais a frente, a família Gaudêncio precisou reinventar seu próprio fazer político e a relação com o eleitorado local.

\section{AS FORÇAS DESORGANIZADAS DO SISTEMA LATIFUNDIÁRIO/MORADIA}

Segundo Moreira e Targino (1997, p. 103), a partir da década de 1970 ocorreram fortes modificações no processo de produção rural na Paraíba, intensificando o processo que no presente trabalho denominou-se de desorganização do sistema latifúndio/moradia, processo este que emergiu e se solidificou por meio de uma série de fatores climáticos e sociais, tais como: transformações na estrutura agrária após a crise do sistema pecuária/algodão/sisal/culturas alimentares/moradia/latifúndio, além das mudanças ocorridas com a industrialização das lavouras, avanço da pecuária em relação a lavouras temporárias, mudanças na política de trabalho assalariado com relação ao sistema de moradia e que deram origem a toda uma mudança nas relações do processo de produção e de pose da terra.

Com base em Moreira e Targino (1997, p. 105) processos como a modernização da agricultura, expansão da pecuária e da lavoura de produtos alimentícios e o agronegócio, proporcionaram profundas alterações na dinâmica de produção do Estado, bem como sobre as condições de vida dos trabalhadores e das classes operárias.

\footnotetext{
${ }^{4} \mathrm{~A}$ expressão coronelismo foi definida por Victor Nunes Leal, em 1949, referindo se aos fazendeiros que recebiam a patente militar no período imperial. A partir da instalação da chamada República Velha (1889 - 1930), estes coronéis incrementaram sua estrutura de poder baseados num sistema eleitoral que não previa a votação secreta.
} 
Na década de1970, segundo Moreira e Targino (1997, p.138) o espaço rural da Paraíba, formado em sua grande maioria por latifundiários, recebeu diversos incentivos como: a criação do Programa Nacional do Álcool $\left(\mathrm{PROALCOOL}^{5}\right)$; forte política de subsídios e incentivos ao crédito fundiário, a baixos custos e com perdão das dívidas, financiados por bancos de fomentos nacionais como Banco do Brasil, Banco do Nordeste, Banco do Estado da Paraíba.

Além dos recursos desses Bancos nacionais e instituições internacionais como o Banco Mundial (BID), houve ainda recursos de órgãos como o Fundo de Investimento do Nordeste (FINOR) e do PROJETO NORDESTE. De acordo com Mello (2002, p. 158), na década de 70 até mesmo as administrações estaduais eram motivadas pelos fomentos agrícolas. Entretanto a partir de meados da década de 80 o meio rural da Paraíba, no que se refere às lavouras de cana-deaçúcar, ao setor algodoeiro e ao sisal, sofreram drásticas mudanças diante da crise econômica e mudanças estruturantes no Brasil, o que acarretou nas formas desorganizadoras do sistema latifúndio/moradia. E para além dessas mudanças, Moreira e Targino (1997, p.125), elencam outros fatores desestruturantes do sistema latifundiário, como: a) Fatores Políticos e econômicos: i) diminuição do crédito fundiário e cobrança das dívidas por parte do Governo Federal, ii) cobrança mais incisiva dos débitos da empresas junto ao INSS e da receita Federal, iii) elevação nos custos da produção da lavoura e dos preços dos transportes, iv) crescimento do agronegócio; b) Fatores sociais: i) perda do poder político e econômico da burguesia canavieira nordestina, ii) mudanças nas relações de trabalho promovidos pelas usinas, iii) organização sindical dos trabalhadores, iv) êxodo rural; c) Fatores naturais e climáticos: i) grandes períodos de estiagem na região, ii) estagnação da pecuária, iii) pragas de insetos como a praga do bicudo que dizimou grande parte das lavouras de algodão no estado, dentre outros problemas.

Todas essas mudanças no sistema latifundiário, marcado tanto por relações de poder, como o fim e/ou transformação no sistema coronelista, e, em seguida, as transformações ocorridas no meio rural, acima apresentadas, dão origem a uma nova forma da relação entre os donos da terra e a sua forma de manter-se no poder, no modo de fazer política, reproduzidas e percebidas nas mesmas relações construídas pela família Gaudêncio na cidade de Serra Branca.

\footnotetext{
${ }^{5}$ O Pró-Álcool ou Programa Nacional do Álcool foi um programa de substituição em larga escala dos combustíveis veiculares derivados de petróleo por álcool, financiado pelo governo do Brasil a partir de 1975 devido a crise do petróleo em 1973 e mais agravante depois da crise de 1979.
} 


\section{A FAMÍLIA GAUDÊNCIO, A TERRA E A POLÍTICA EM SERRA BRANCA}

A origem de Serra Branca, segundo relatos orais, remeteu-se as fazendas de gado instaladas às margens dos rios Poção e Jatobá, as quais com suas cacimbas forneciam água para as famílias e rebanhos, seguindo as características do processo de colonização do restante do interior da Paraíba e, do Nordeste, onde o surgimento dos povoados ocorreu em prol da expansão da pecuária. Ressalta-se que conforme as relações de trabalho desse período, os fazendeiros construíam as casas para seus trabalhadores, cediam pequenas terras para os roçados e faziam de suas casas o centro do cotidiano da sociedade. Como pontuam Moreira e Targino:

Os moradores eram camponeses sem terra que recebiam do proprietário fundiário a autorização de habitar na propriedade, ocupar um pedaço de terra (os sítios) e nele cultivar uma roça. Em alguns casos, podiam criar animais pequenos, médios e de grande porte. Tinham direito a lenha e a água. (Moreira e Targino 1997, p.43).

Logo, todos os trabalhadores deviam obediência ao chefe que tomava conta da "organização da família", que detinha por direito divino os domínios terrenos. Logo, conforme Moreira e Targino (1997, p.44), o modo de moradia, das condições trabalho e de sobrevivência mantinha uma estreita relação com o acesso a terra.

Nesse contexto histórico, configurada como proprietária de grandes extensões de terra, a família Gaudêncio, porta-se como representante de toda a região do Cariri, e assim, vêem aparecer em Serra Branca uma nova fonte econômica e eleitoral para suas intenções políticas, pois como a maioria das cidades da Paraíba, em Serra Branca, o poder local estava fortemente marcado pelas relações de mando da terra, pela posse das grandes propriedades rurais.

A família Gaudêncio firma-se como monopolizadora dos destinos econômicos, sociais e políticos de Serra Branca, porém, com a crise do sistema latifúndio/algodão/pecuária/moradia, da economia algodoeira, da praga do bicudo e, principalmente, com as mudanças das relações de trabalho no campo - marcado pelo trabalho assalariado, mesmo que este fosse temporário como nas usinas de cana de açúcar, que surgiram a partir da década de 1970 e meados da década de 1980, intensifica-se o processo de transformação e mudança social nas médias e grandes propriedades, dando início a um cenário econômico e político no País, no Nordeste, na Paraíba e, 
por fim, no Cariri Ocidental, onde o latifúndio deixa de ser a forma social dominante das grandes propriedades.

Como Oliveira (1981, p. 35) pontua, antes da desorganização do latifúndio, no Nordeste algodoeiro-pecuário, "coronéis do algodão, pecuária [...] são os agentes e a forma da estrutura do poder". Dessa forma, era nesse cenário que se encontrava a família Gaudêncio, como representante legítima do poder local da cidade de Serra Branca, e cujo nome era inserido na política estadual e nacional.

A marca principal das propriedades da família Gaudêncio era a produção de algodão, tendo sido esta uma das principais culturas agrícolas do Nordeste e a única a enfrentar a cana-de-açúcar com algum êxito. Contudo, as fortes transformações ocorridas no meio rural, especificamente na desorganização do sistema latifúndio/moradia, foram impulsionadoras das mudanças na relação com a terra e todo o fazer social que ocorreram na cidade de Serra Branca e, maiormente sobre sua relação com a família Gaudêncio, que diante do fato reelaboraram o seu papel de elite local, se reinventando através de seu próprio fazer político e das relações com a população.

Nos seus estudos de 1975, Leal apresentou uma conjuntura econômica marcada pela decadência dos fazendeiros que em face à perda de seu poder, passaram a exigir a presença do Estado como forma de garantir a manutenção de seu poder político em benefícios de seus dependentes e rivais. Assim, para Leal (1997, p.40), o coronelismo não é mera sobrevivência do poder privado:

[...] resultado da superposição de formas desenvolvidas do regime representativo a uma estrutura econômica e social inadequada. [...] É antes uma forma peculiar de manifestações do poder privado, ou seja, uma adaptação em virtude o qual os resíduos do nosso antigo e exorbitante poder privado tem conseguido coexistir com o regime político de extensa base representativa.

Como acontecia em todo o sistema oligárquico do país, nos municípios os coronéis ${ }^{6}$ decidiam a política local. Então, o coronelismo caracterizava-se como um fenômeno político e social, com raízes na tradição patriarcal brasileira e na estrutura agrária, onde se definia certas práticas políticas e sociais próprias do meio rural brasileiro, com seus subprodutos de pobreza, ignorância e dependência social.

\footnotetext{
${ }^{6} \mathrm{~A}$ expressão coronelismo foi definida por Victor Nunes Leal, em 1949, referindo se aos fazendeiros que recebiam a patente militar no período imperial. A partir da instalação da chamada República Velha (1889 - 1930), estes coronéis incrementaram sua estrutura de poder baseados num sistema eleitoral que não previa a votação secreta.
} 
Por fim, concedia-se a patente de coronel à grandes latifundiários que exerciam total controle sobre seus agregados e outras pessoas que dependiam de sua influência. Assim, Leal (1975) afirma que coronel era todo grande latifundiário, dono de grande contingente de terras, detentor de numeroso rebanho de gado e outros animais. Ainda de acordo com esse autor, o coronel desfrutava de grande prestígio junto às autoridades do Estado, tanto na esfera Federal quanto na Estadual, mantido através da troca de favores. Ou seja, os coronéis asseguravam a vitória em suas regiões de atuação aos políticos e em troca conseguiam alguns benefícios para a população carente na área da saúde ou da educação, e cobravam dessa população lealdade e obediência a sua orientação política. Ao coronel também cabia a função de resolver as questões de justiça em seus domínios.

A família Gaudêncio, como objeto deste estudo social, propiciou aventar as relações da posse da terra e a trama com as estratégias políticas, não apenas no município, mas entre as diversas camadas administrativas e sociais, onde na maioria das ações agia sob as práticas coronelistas de mando descritas por Leal (19780).

Dessa forma, a família Gaudêncio, inserir-se em uma disputa que Moreira (2012, p.33) denomina de busca pela "chefia suprema". A estrutura política social desta busca, em que o poder de mando é o principal agente de legitimação de identidades, pode ser avaliada a partir do estudo do conceito de "coronelismo".

Como dito anteriormente, a partir da década de 1970 e meados da década de 80, o processo de transformação social nas médias e grandes propriedades, iniciou um cenário econômico e político no País, onde o latifúndio deixou de ser a forma social dominante das grandes propriedades. Nesse cenário, encontrava-se a família Gaudêncio, como representante legítimo do poder local na cidade de Serra Branca, sendo proprietária de grandes extensões de terras. Tendo seu nome inserido na política estadual e nacional, pelo seu poder como grandes proprietários de terra.

Como mencionado e enfatizado anteriormente, o Cariri Ocidental da Paraíba tem seu processo de povoamento marcado pela introdução da cultura do algodão como modo de produção, diante do fato de que o litoral era campo quase que exclusivo para o plantio dos canaviais, logo, a medida que o gado ia avançando pelos sertões atrás de pasto (a pecuária nordestina por muito tempo foi extensiva, ou seja, o gado era criado livre, eliminando assim a 
necessidade do dono procurar pastos para alimentá-lo). Então, com o desbravamento dos Cariris, o algodão e outras culturas passaram a ser estabelecidas na região, permitindo que grupos de famílias ocupassem as terras e construíssem suas fazendas especialmente voltadas para a cotonicultura e pecuária de pequeno porte. A partir das décadas de 1970 e 1980, diante de inúmeros fatores acerca do processo de produção, intensifica-se a crise do sistema produtivo formado por elementos como as relações de moradia, da pecuária e da cotonicultura, processo que historicamente estavam sob o comando político e ideológico das elites latifundiárias. Diante desse novo contexto, o presente trabalho buscou compreender como a família Gaudêncio vivencia as transformações desse processo e constrói sua trajetória familiar ora pela terra, ora pela política, e de como se dá a influência dessa família no Cariri Paraibano e em especial na cidade de Serra Branca/PB.

Diante desta situação, foi travado um debate marcado pela ideia de como a posse de grandes propriedades de terras podem influenciar o poder de um grupo, de uma elite, na vida social e política de uma cidade, e de como a produção agrícola transformada de um capital financeiro e, posteriormente, em capital simbólico pode interferir na vida social de uma região, em especial na cidade de Serra Branca, através do estudo de caso do grupo familiar Gaudêncio.

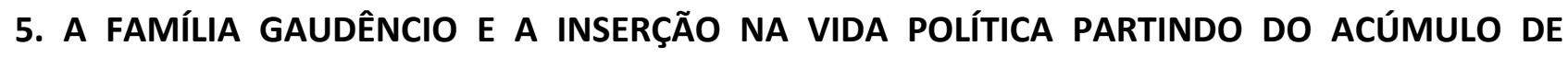 CAPITAL}

A origem da família Gaudêncio, que primeiramente é a família Correia de Queiroz (MEDEIROS, T. D; MEDEIROS, M. D, 1989 p.15), é descendente de Pascácio de Oliveira Lêdo, sobrinho de Teodósio de Oliveira Ledo: "O conquistador dos sertões da Paraíba", tendo a família Correia de Queiroz como família de origem e Joaquim Correia de Queiroz, proprietário da fazenda Uruçú, como patriarca. 
Durante o século XVIII as missões jesuítas deram origem ao processo de povoamento da região denominada de "Cariri Ocidental", configurando o povoado como o principal centro populacional da microrregião. Segundo Moreira (2012, p.48), a família que prevaleceu no poder em São João do Cariri durante o império foi os "Costa Romeu". Seu principal patriarca na região, Antonio da Costa Romeu, tinha na base rural sua fonte de riqueza da família, visto que na ocasião era proprietário de muitas terras, as quais foram herdadas do Capitão-Mor Domingos da Costa Romeu, seu tio legítimo. E de acordo com Borba (2014, p.23), além das terras, o Capitão-Mor Domingos da Costa Romeu tinha a seu cargo, a defesa da Vila de São João do Cariri contra ataques externos e também o poder de polícia. Assim, Antonio da Costa Romeu contraiu casamento com a filha do Capitão-Mor (sua prima legítima), e tornou-se o patriarca de diversas famílias no Cariri paraibano. Dessa forma, a família Costa Romeu teve grande prestígio no cenário político local, o que levou seus membros a ocuparem diversos cargos legislativos durante a primeira república.

Conforme Moreira (2012, p. 51apud 1930 MEDEIROS, T.D; MEDEIROS, M. D, 1989,p.206209), a família Correia de Queiroz chegou de Pernambuco para o Cariri na segunda metade do século XVIII, com o casamento entre Joana Batista do Sacramento e o pernambucano João Batista Correia de Queiroz. O filho de João Batista, o Capitão e Comandante João Crisóstomo Correia de Queiroz (1779-1849) casou-se com Ana Felícia de Brito Maciel, bisneta paterna de José da Costa Romeu e neta materna de José de Brito da Câmara. O filho de João Crisóstomo, Joaquim Correia de Queiroz, casou-se com uma prima, Teresa Maria das Virgens, bisneta de José da Costa Romeu observou-se aqui que a riqueza da família se sustentava pelo casamento endogâmico que garantia a posse da terra e a manutenção do latifúndio. Entretanto, diante das querelas de parentela, a família que era única se separa dando origem a duas novas famílias: uma encabeçada por Higino da Costa Brito, décimo segundo filho de Antonio da Costa Romeu e a outra por Joaquim Correia de Queiroz que posteriormente passa por herança para Maria José de Queiroz (Dona Mariquinha), esposa de Manoel Gaudêncio de Queiroz.

A família só se torna de fato "Gaudêncio" a partir dos filhos de José Gaudêncio Correia de Queiroz, filho por sua vez de Maria José de Queiroz e Manuel Gaudêncio de Queiroz, que conforme informações de Moreira $(2012$, p.50) eram primos diretos e proprietários da fazenda Uruçu, no município de São João do Cariri. A família adotou a partir daí o sobrenome Gaudêncio Correia de Queiroz, família que anteriormente era apenas Correia de Queiroz, uma vez que "Gaudêncio" era nome próprio. 
Segundo (MEDEIROS, T.D; MEDEIROS, M.D. 1989, p.14), o nome Gaudêncio passou a ser capital simbólico da família devido à influência de José Gaudêncio na política do Estado durante a oligarquia epitacista. Manoel Gaudêncio passou assim a batizar todos os seus filhos com o nome "Gaudêncio" como sobrenome.

Nesta origem da família Gaudêncio, liderada pelo então Coronel ${ }^{7}$ Manoel Gaudêncio, a mesma não era a maior proprietária de terra no sentido de possuidoras de grandes extensões territoriais. Entretanto, apresenta-se no Cariri Ocidental da Paraíba como uma das maiores produtoras de algodão, em especial no território que compreende a então cidade de São João do Cariri e o distrito de Serra Branca, destacavam-se no cenário em todo o território estadual .

Com base na genealogia da família Gaudêncio, corroborou-se com a percepção de Pierre Bourdieu (2001) quando ele enfatiza que as relações de poder fundamentalmente adquiridas pelo capital propiciam também a construção de outras relações de poder. Uma vez que:

[...] relações de poder que dependem, na forma e no conteúdo, do poder material ou simbólico acumulado pelos agentes (ou pelas instituições) (...) cumprem a sua função política de instrumento de imposição ou de legitimação da dominação, que contribuem para assegurar a dominação de uma classe sobre outra (violência simbólica) dando o reforço da sua própria força às relações de força que as fundamentam contribuindo assim, segundo a expressão de Weber, para a 'domesticação dos dominados' (BOURDIEU, 2001, p.11)

Diante desse conceito a sociedade é organizada pelos campos, os quais são estrutura estruturada e neles se encontram os dois pólos: os dominantes e os dominados. Ao primeiro, está relacionado à maior dimensão do quantum, ao maior acúmulo de capital; ao segundo se relaciona a raridade de capital. Quanto maior for à quantidade de capital acumulado, mais o indivíduo tende a ser dominante no campo. E assim, partindo da necessidade desse acúmulo de capital visando a transformação do capital econômico em outro tipo de capital capaz de gerar, produzir e fortalecer diversas relações sociais como a de dominação, a família após a inserção na vida política e tendo destaque no cenário nacional,a partir da década de 1970 começa adquirir terras tornando-se uma das maiores proprietárias da região.

\footnotetext{
${ }^{7}$ Titulo outorgado pelo governo que oficializava, o poder dos oligarcas, isto é dos grandes proprietários de terras. Eles já não eram somente uma autoridade de fato, mas também de direito, uma vez que tinham o respaldo de uma instituição do governo central.
} 
A partir do século XIX segundo Mariz (1978, p.18), todo o Cariri passou por um forte processo de urbanização e, Serra Branca em especial, tornou-se um dos principais centros da produção da cultura de Algodão. Diante disso, a população do pequeno distrito que era então controlada pelos fazendeiros e pequenos agricultores criaram laços de dependência que se manifestaram na cultura política local.

Junto com as mudanças na produção algodoeira ocorreram também mudanças na relação de trabalho. Visto que com o fortalecimento do coronelismo em regiões algodoeiras no Estado da Paraíba, a produção algodoeira e as relações de trabalho estavam intrinsecamente ligadas à cultura política que perdurou durante a República Velha e teve permanências pós-1930.

O capital financeiro adquirido por meio da fazenda Uruçu e da produção de algodão permitiu que o filho mais velho de Manuel Gaudêncio de Queiroz, José Gaudêncio de Queiroz fosse estudar Direito na Faculdade de Direito de Recife, onde se titula Bacharel em Direito e, ingressa posteriormente na política.

No campo político, concebe-se este enquanto espaço de prática e de disputa, onde se encontra a concorrência por determinados tipos de bens simbólicos, como por exemplo, o poder, que é o elemento essencial de disputa dentro do campo político. Em torno disso, ou melhor, em busca desse bem, o campo se estrutura a partir de toda uma distribuição desigual de capital, assim começa uma luta desigual, dado que existem os agentes que possuem mais capital político que outros. Estes capitais possuídos por determinados indivíduos mais do que por outros é o que possibilita a diferenciação, a distinção, ou seja, este "traço distintivo, propriedade relacional que só existe em relação a outras propriedades" (BOURDIEU, 1996, p.18).

\subsection{A FAMÍLIA GAUDÊNCIO}

E de fundamental importância salienta-se que naquele momento quem detinha o capital econômico possuía, quase sempre, "capital social” e, conseqüentemente, podia converter o capital político e capital político-familiar por meio do qual os herdeiros das oligarquias se inseriam no campo de disputas. Pois, conforme visto em (SOUZA 2015 apud MONTEIRO, 2016 pp. 82), "os agentes que detêm capital econômico e capital cultural ocupam as melhores posições, os herdeiros das oligarquias, estudam nas melhores escolas de formação, possuem 
capital econômico". Assim, há uma relação diretamente proporcional, ou seja, quanto maior o volume de capital maior será a probabilidade dos agentes dessas famílias assumirem os principais cargos. O acesso, portanto, pode ser medido ou mensurado por meio do volume de capital.

O grupo familiar existe enquanto criação social que é capaz de reproduzir estruturas existentes, e seus interesses são múltiplos. Em uma ordem societária capitalista, a ampliação do capital econômico se torna um dos interesses centrais. E o capital político-familiar é um desses capitais que se converte em capital econômico. É a esfera da política um dos espaços nos quais a família torna-se estratégica no sentido de ampliação dos capitais: político, econômico e familiar. Alves (2015) informa que:

[...] uma estrutura em que o capital econômico prevalece, a família, enquanto corpo com sentimentos recíprocos de proteção, levaria-os a perpetuar, ou mesmo ampliar as conquistas já adquiridas, protegendo os seus próprios membros. (ALVES, 2015, p. 28)

Neste sentido, é após a inserção de José Gaudêncio na vida política, primeiramente enquanto juiz de direito e depois como senador, que a família Gaudêncio dá início a sua trajetória política e sua consolidação enquanto grupo oligárquico presente no cenário estadual, chegando a ocupar espaço no cenário nacional.

Presente na vida política da região do Cariri há aproximadamente 100 anos, a família Gaudêncio despontou no cenário do poder local da então cidade de São João do Cariri e na disputa entre Britos e Gaudêncios, em Serra Branca e São João do Cariri. Sublinha-se que naquela época a região de Serra Branca era distrito de São João do Cariri e só passou a ser município no ano de 1960, porém mesmo antes da municipalização da cidade, os Gaudêncios já exerciam poder político nessa região. E a ligação inicialmente desta família com a vida política darse por meio do poder ganho, obtido a partir da aquisição da terra, e, em especial, da aquisição da fazenda Uruçu pela herança recebida por Maria José de Queiroz, conforme foi mencionado na sessão anterior. Com o capital econômico obtido com o usufruto da fazenda herdada, José Gaudêncio foi estudar Direito na Faculdade de Direito de Recife - oportunidade que apenas os 
grupos oligárquicos e as famílias abastadas da Paraíba podiam proporcionar aos jovens membros das famílias -, chegando depois ao poder a partir de suas atuações como juiz, em São João do Cariri. Ser proprietário de terra e, posteriormente, adentrar no curso de Direito era, portanto, parte da construção de um futuro político, pois "era na magistratura que os partidos colocavam os jovens com vocação para a vida pública" (TRIGUEIRO, 1982, p. 171).

Dessa forma, o ingresso de José Gaudêncio na política foi o ingresso também da região do Cariri, através de São João do Cariri na participação de vários momentos da política paraibana, inclusive apoiando João Suassuna e o Coronel José Pereira no levante de Princesa Isabel em 1930.

Diante desse apoio, José Gaudêncio conseguiu a indicação para tornar-se Senador da Republica - é em sua homenagem que a Escola Estadual do município recebeu o nome de Senador José Gaudêncio -, visto ser este um cargo indicativo e não eletivo. E embora tenha perdido o mandato com a Revolução de 30, o passo inicial do Senador José Gaudêncio na política, abriu caminho para as trajetórias familiares, pois depois dele todos os irmãos, participaram de disputas políticas, a exemplo de Álvaro Gaudêncio de Queiroz que era o irmão mais novo; Joaquim Gaudêncio de Queiroz; o Padre Apolônio Gaudêncio de Queiroz que chegou a ser candidato à prefeitura de São João do Cariri nos anos 30 e Joaquim de Queiroz que foi eleito prefeito de São João do Cariri em 1947.

A partir da indicação de José Gaudêncio ao senado, a então família Gaudêncio, que tinha como atividade principal as fazendas de algodão, assumiu uma trajetória política não apenas no estado, mas no cenário nacional. O que fez com que as relações de poder e, consequentemente, o modo de fazer política, da família Gaudêncio sofresse modificações. Pois, o poder político da família Gaudêncio que teve origem por meio do capital econômico advindo da propriedade rural, acompanhou as mudanças no cenário mundial: como a crise do sistema latifundiário que se intensificou com as mudanças da política da terra; como as transformações do sistema de moradia e as alterações nas relações naturais a exemplo da praga do algodão e a acentuação dos períodos da seca, moldando uma nova forma de fazer política, sendo agora através desse acúmulo de capital financeiro. Ou seja, a partir do momento que houve a ascensão política de José Gaudêncio de Queiroz, o Senador Jose Gaudêncio adquiriu influência política ao nível de estado visto à ligação com o governador do Estado. Isso proporcionou a família uma ascensão não só política, mas também patrimonial, a julgar pelos cargos políticos e funções públicas que a família começou a 
operar, eles começaram também a crescer territorialmente, no sentindo de aquisição de outras propriedades, entre São João do Cariri e Serra Branca, como por exemplo a compra da Fazenda Areias que inicialmente era de propriedade de Joaquim Gaudêncio de Queiroz, mas foi vendida posteriormente ao um senhor chamado Antero da Cunha Torreão Junior, casado curiosamente com uma irmã de Joaquim Gaudêncio de Queiroz.

A família passou então a investir na terra não como meio de sobrevivência econômica, mas como forma de poder político, no intuito de ajudar a família nos momentos importantes das grandes disputas políticas, em especial, entre as disputas de poder de Brito e Gaudêncio pelo poder entre Serra Branca e São João do Cariri. A terra passou então a ser capital simbólico, capital de dominação. O poderio político do coronel estava aliado ao poderio fundiário. Possuidor de grandes fazendas enquanto base eleitoral.

Então, a partir dos anos 50 as repercussões políticas da família Gaudêncio - assim como nos anos 1960, 1970, 1980, período de Ditadura Militar -, se dá não mais pelo poder da terra e sim pela influência política, através da reinvenção da política. Como exemplo da força dessa reinvenção na forma de fazer política, cita-se a aliança com o governador do Estado da Paraíba, João Agripino que foi aliado político "dos Gaudêncio" durante toda a sua trajetória política, além de Ivan Bichara e Pedro Gondim, fortes aliados da família no cenário estadual e nacional.

Nesse sentido, essas alianças com outras forças políticas do Estado passaram a ser forte instrumento de alcance de prestígio político que propiciavam ganho de cargos políticos, de prefeituras, de poder executivo na prefeitura de São João do Cariri ou Serra Branca, etc. Uma nova forma de fazer política foi marcada, a família começou a se mantém no poder público através do populismo e das alianças conquistadas.

E assim, conforme Monteiro (2009, p. 40) a história da família Gaudêncio em Serra Branca é uma história de dominação política econômica, cultural e territorial. O espaço foi ocupado por diversos agentes, e coube aos agentes das famílias tradicionais o domínio sobre as melhores terras, os melhores espaços físicos territoriais. Logo, este espaço físico-territorial foi construído a partir de um espaço na ordem no campo do poder. Como uma família tradicional, a família Gaudêncio em Serra Branca, possuía sobre o espaço do município as melhores terras, o maior número de trabalhadores atuando em suas terras - em uma determinada época do ano queimando o sisal e em outra plantando e colhendo o algodão, o milho e o feijão. Portanto, foi do 
"tronco" que essa família exerceu domínio e poder sobre as relações trabalhistas locais, que se tornou historicamente reconhecida como a "possível nobreza" da região e, posteriormente, assumiu o poder do município. Fazer parte dessa família ou ter o mesmo "sangue", é possuir capitais simbólicos que tornam esses agentes diferentes dentro do campo político, visto que a família Gaudêncio em Serra Branca está na vida política da cidade desde muito antes de sua fundação, e em 56 anos de trajetória política da cidade, e conforme dados dos registros do TRE/PB, 40 anos foram sob administração política desse grupo, tendo apenas pequenos episódios de interrupções por derrotas eleitorais.

Entretanto, diferente de outros grupos familiares do estado da Paraíba, a família Gaudêncio a partir da década de 1980 começa sofrer derrotas tanto a nível local quanto a nível estadual, que enfraquece sua representatividade na conjuntura política nacional. Essa perda na representatividade política, coincidentemente ocorre justamente no recorte temporal desta pesquisa, que denominamos como desorganização do sistema latifúndio/moradia e embora muitos os membros da família não atribuam essa perda de poder político das tradicionais formas de fazer política, marcadas pelo domínio do capital do latifúndio como os sistemas de moradia e ou de coronelismo, cabe a partir de então investigarmos quais seriam as causas dessa perda de poder desse grupo político e de como os mesmos refazem suas estratégias e práticas, construindo assim todo um modo de fazer política.

\section{REINVENÇÃO DO FAZER POLÍTICO DA FAMÍLIA GAUDÊNCIO EM SERRA BRANCA}

Quando se pensa na relação existente entre a posse da terra e o fazer político, buscase entender a força e as relações entre estes dois elementos (terra/poder). A partir dessas relações, percebe-se que, conforme Monteiro (2016, p.132), as heranças simbólicas das famílias são permeadas de relações que Ihes possibilita atuar no campo de disputas, a partir de acúmulos de capitais como as grandes propriedades ou dos recursos que elas geram. Assim sendo, conforme Bourdieu (2001), esses agentes são construtores e protagonistas de 
inúmeras relações sociais a partir dos espaços que ocupam. E mesmo diante de uma série de fatores, que se denominou nesta pesquisa de crise do sistema latifúndio/moradia, que culminaram em uma mudança na forma do fazer político e ou de estar no poder, conforme Leal (1975), essas transformações do sistema agrário resultaram no enfraquecimento da conjuntura econômica e política, pois atingiram o poder dos donos das terras ${ }^{8}$, que por sua vez exigiram a presença do Estado, expandindo ao mesmo tempo a influência política.

Porém, mesmo após todo esse processo de desorganização, os grupos políticofamiliares continuam presentes no cenário político local, embora não estejam em cargos eletivos, apresentam-se como líderes ou referências políticas das pequenas cidades, como no caso de Serra Branca.

No que se refere à família Gaudêncio, embora ela tenha perdido significativo prestígio social nos cargos políticos eletivos do Estado ao longo das últimas duas décadas, detém forte representação na conjuntura da cidade de Serra Branca, ora como grupo, ora de forma individual tal como no momento final dessa pesquisa, onde os entrevistados não formavam um grupo familiar coeso em razão de terem participado como adversários políticos nos três grupos que disputaram o pleito eleitoral de 2016. Nesse contexto, os membros da família Gaudêncio estão sempre presentes na política local. Assim, enquanto líderes tradicionalmente constituídos, (re)criam e re(in)ventam-se politicamente.

\subsection{ROMPENDO COM O PASSADO DO CORONELISMO AO PODER CARISMÁTICO}

Ao longo de toda a história de Serra Branca, são inegáveis a influência e o domínio político da família Gaudêncio através da liderança política de seus representantes. Uma família que teve seu nome na política não apenas no Estado da Paraíba, mas também a nível Federal.

O poder político do grupo foi construído a partir do ingresso no cenário político através de outros capitais para além da materialidade das grandes extensões de terras que passaram a possuir e a concentrar. Um poder que surgiu baseado no sistema político denominado de

\footnotetext{
${ }^{8}$ Para Vitor Nunes Leal em seu livro denominado coronéis
} 
clientelismo e/ou mandonismo local fortemente arraigado nas formas "coronelistas" do fazer político.

Fortunato (2008 p.47) ratifica que por ser um dos sistemas mais fortes no jogo de poder na Paraíba, o coronelismo propiciava um conjunto de práticas de dominação política, se instituindo como resultado das lutas estabelecidas entre as classes sociais fortemente marcadas pela concentração da terra, vínculo entre o econômico e o político, ora como fenômeno que ocorre muito mais no plano político.

É nesse cenário que por muito tempo esteve à família Gaudêncio destacada como importante produtora de algodão. Conforme Maia (2013, p. 52), as famílias proprietárias de terras eram as que detinham mais poder econômico e político na Paraíba. Estas não eram simples agricultoras, porquanto que representavam uma burguesia agrária, arquitetavam a oligarquia do Estado. Uma família que não detinha um pedaço de terra dependia economicamente dos proprietários, e estes por sua vez, dependiam da força do trabalhador, esses laços recíprocos reforçavam o controle do campo pela classe latifundiária. Nesse contexto, os que não dispunham de terras tinham de se subordinar as imposições dos grandes proprietários. Essas relações entre donos de terras e trabalhadores rurais constituíam uma verdadeira exploração, através de relações de compadrio, favoritismo, dentre outras práticas produzidas pelas relações pessoais de produção.

No caso da família Gaudêncio, além de terem grandes extensões de terras as quais possuíam barragens, que em épocas de seca, eram liberadas para a população mais carente para que pudessem utilizar as águas para suas necessidades diárias como caça, pesca e plantio de várias culturas, em especial a cotonicultura, pelo sistema de meia e/ou terça parte da produção, a família conseguia, também, através de sua influência pessoal, empregar várias pessoas residentes no município junto aos organismos públicos. Todos esses elementos eram utilizados como formas de construir laços sociais através da "prática de favores".

Assim, segundo Lewin (1993 apud Maia, 2013, p.54), no final de 1880 os membros de famílias tradicionais da Paraíba ocuparam cargos municipais, estaduais e até federais, sempre protegendo seus interesses econômicos. Sublinha-se que os filhos ou mesmo a parentela ${ }^{9}$ desses

\footnotetext{
${ }^{9}$ Linda Lewin analisa a ascensão e a queda de uma oligarquia que dominou o cenário político na Paraíba dos fins do século XIX até 1930. Epitácio Pessoa, seu líder por volta de 1911, foi ministro da Justiça, procurador geral, senador e presidente - e por fim membro da Corte Mundial de Haia. O livro enfoca a parentela (família extensa), incluindo a de
} 
senhores de terra também ocupavam cargos de juízes e tabelião dos municípios que comandavam. O poder e o prestígio conquistado através de estratégias sociais, econômicas e políticas permitiu que esses grupos familiares fossem gradativamente adquirindo terras, ao mesmo tempo em que construíam seu fazer político através do acúmulo de cargos políticos, como no caso da família Gaudêncio. , A família Gaudêncio construiu seu patrimônio político a partir da construção de seu patrimônio territorial, posto que na década de 1980 torna-se a maior detentora de terras da região. Como em um jogo de cartas marcadas, o chefe da família elitizada financiava o estudo dos filhos nos maiores centros, como a cidade de Recife e João Pessoa e assim, quando formados os filhos serviam como elo crucial entre o município e o sistema político a nível estadual e nacional. A consolidação da estratégia consistia em manter a dominação do município de São João do Cariri e, por conseqüência dos fatos conforme anteriormente apresentados, de Serra Branca. Por fim, já com os filhos bacharéis, médicos e padres, a família Gaudêncio projetava as redes políticas de base familiar em cada camada de detenção de cargos políticos e burocráticos.

Conforme Maia (2013), a partir da década de 1970 até meados da década de 1980, intensificou-se o processo de transformação social nas médias e grandes propriedades, após a desorganização do sistema latifúndio/ algodão/ pecuária/moradia, iniciando um novo cenário econômico e político no país.

Para Bursztin (2008, p.32), "o velho coronel encontra uma forma de prolongar sua vida, a qual estaria, em tese, condenada pela própria evolução do capitalismo". Para Bursztin (2008, p.49) o Estado se torna o regulador ativo, visando o desenvolvimento direto do setor agrícola enquanto estrutura produtiva, com instrumentos como o apoio ao crédito rural, fortalecimento do cooperativismo. Essas transformações foram fortemente sentidas no nível de estrutura fundiária, pois as alterações nas relações de produção causam tanto mudanças quantitativas quanto qualitativas. Entretanto: 


\begin{abstract}
adotada pelo estado representa ao mesmo tempo um mecanismo de reforço de coronéis. Ou melhor, trata-se de um processo simultâneo em que o estado inviabiliza parcialmente o coronelismo ao mesmo tempo que uma boa parte dos coronéis sobrevive graças ao estado. (BURSZTIN, 2008, p.54)
\end{abstract}

Neste contexto, a família Gaudêncio buscou estratégias para a construção da relação com os munícipes e eleitores, construindo uma trajetória fortemente arraigada na forma de poder carismático, em que demonstrava simplicidade, mas, ao mesmo tempo, exercia dominação.

A partir da ruptura com o modo coronelista do fazer político, a família Gaudêncio buscou novas formas de fazer política, ora dando emprego para diversas pessoas nos setores que exercia influência, ora trazendo para a cidade equipamentos públicos, como agências bancárias, postos do Instituto Nacional de Seguridade Social, etc. Ou seja, sempre usando práticas assistencialistas e/ou clientelistas para manter-se no poder, diante do fato de que o poder agora não mais viria apenas pela influencia e dominação propiciado pela terra, foi instituída uma forte ligação entre as pessoas da cidade de Serra Branca e à liderança da família Gaudêncio. O poder da família não veio somente da terra e dos laços de parentela, ele veio da força invisível que fez com que a sociedade legitimasse esse poder. Onde fica evidenciado o desejo de autonomia local para perpetuação do mandonismo e os recorrentes laços entre as famílias da elite para continuarem no poder.

O poder do latifúndio da família Gaudêncio forma-se a partir da área do cultivo do algodão na cidade de São João do Cariri. A família passou a construir um nome e a demarcar seu território. Com a inserção de José Gaudêncio na política, a família construiu laços e redes que os levaram a proximidade com a Presidência da República, laços que confirmaram a existência do poder oligárquico em nosso Estado.

A figura do deputado federal Álvaro Gaudêncio Filho era o principal nome político da família, tendo sido prefeito, deputado estadual e representante do Cariri como Deputado Federal. Quando ele vinha uma vez por mês visitar o município, hospedava-se na fazenda de Lagoa de Cima, no então distrito de Coxixola. Era um verdadeiro evento local, quando diversos representantes deslocavam-se de seus distritos para audiência com o Deputado em busca de favores. O deputado mandava matar um dos maiores bois de sua fazenda para alimentar todos que vinham, como uma forma de demonstração de sua "generosidade". 
Entretanto, com o passar do tempo, a relação entre os membros da família Gaudêncio apresenta mudanças, quase todos os descendentes migraram para os grandes centros, fragilizando de certa forma a ligação com Serra Branca e a política local. No decorrer de todo esse processo, a família elaborou, vivenciou e reinventou inúmeras estratégias de dominação que foram incorporadas nos agentes locais, como se fossem naturais. Assim, falar de Gaudêncio na política é também falar de suas vivências, histórias e memórias em Serra Branca, uma vez que, conforme Monteiro (2016), "os corpos passam a ser o espaço do exercício da dominação e da incorporação dos valores construídos por um pequeno grupo que tem um maior quantum de capita".

Entretanto, nas últimas décadas e, em especial entre 1970 e 1980, a família Gaudêncio gradativamente perdeu representantes políticos no cenário estadual e nacional, e embora o poder político continue em Serra Branca, os mesmos contam com baixa representatividade em cargos eletivos.

Uma das grandes questões levantadas na pesquisa foi investigar se essa redução da família na política se dá ou não mediante as mudanças ocorridas no período que se compreendeu aqui como a intensificação da crise do sistema latifúndio/moradia. Tentou-se também compreender, a partir de então, como os representantes dessa família se percebem enquanto detentores "legítimos" da representação do poder público local.

Nas últimas décadas, a família vem buscando seu reinventar político, agora não mais pelo poder advindo das grandes propriedades produtoras de algodão, mas por um modo de fazer política que proporcione a continuidade da família tradicional. A família Gaudêncio não faz mais o uso do poder e do capital econômico ${ }^{10}$ advindo das propriedades produtoras de algodão que Ihe permitiu por tantas décadas manter o poder do capital social e suas inúmeras redes de relações sociais que proporcionavam benefícios em sua posição e, em muitas vezes, a submissão de pessoas em busca dos favores nos equipamentos do Estado, enfraquecendo assim o acesso aos cargos políticos.

\footnotetext{
${ }^{10}$ Bourdieu (1989) vê o espaço social como um campo de lutas no qual os atores (indivíduos e grupos) elaboram estratégias que permitem manter ou melhorar sua posição social. Estas estratégias estão relacionadas com os diferentes tipos de capital. O capital econômico, sob a forma dos diferentes fatores de produção (terras, fábricas, trabalho) e do conjunto de bens econômicos (dinheiro, patrimônio, bens 40 materiais) é acumulado, reproduzido e ampliado por meio de estratégias específicas de investimento econômico e de outras relacionadas a investimentos culturais e à obtenção ou manutenção de relações sociais que podem possibilitar o estabelecimento de vínculos economicamente úteis, a curto e longo prazo.
} 
Ou seja, a reprodução do capital social, que é produto do trabalho necessário para produzir as redes de relações duráveis que podem proporcionar os benefícios materiais e simbólicos que circulam entre os membros da rede. Nessa perspectiva, destaca-se a importância do capital social para as diversas frações de classe, pelas possibilidades que sua participação em determinados grupos ou redes sociais Ihes abrem, no sentido de aumentar o rendimento possível do seu capital social e de seus investimentos escolares, na forma de benefícios simbólicos.

Compreender o papel das redes de relações sociais é entender que as mesmas vão além das relações familiares, com uma infinidade de tamanhos e de qualidades. Neste sentido, todos os membros da família Gaudêncio aqui entrevistados afirmaram ter uma divida moral para com Serra Branca, o que justificaria assim sua continuidade na vida política, mesmo diante da acentuada queda de sucesso nos pleitos eleitorais. Ou seja, pensar-se a relação entre a família Gaudêncio e a cidade de Serra Branca é compreender que o individual, o pessoal e o subjetivo são simultaneamente sociais e coletivamente orquestrados. Dessa forma, deve-se vê-lo como um conjunto de esquemas de percepção, apropriação e ação que é experimentado e posto em prática, levando em consideração que as conjunturas de um campo o estimulam.

\section{CONSIDERAÇÕES FINAIS}

Ao término deste trabalho buscando de forma metódica e cientifica compreender todo o contexto de dominação não apenas simbólica que existiu e existe em Serra branca através da família Gaudêncio, tentando compreender quais as relações existentes desse poder local, tão presente, tão dinâmico, tão constante e como ele pode estar ligado ao poder da terra, ao latifúndio. Mas não somente por ela, posto que nela estão os sentimentos vividos, as angústias e os sonhos que incorporados a minha pessoa, fazem parte da minha história, ao mesmo tempo em que fazem parte da história do município em que resido. Percebi, desta feita, que o exercício da dominação está relacionado à eficácia do poder, mas este não é um poder apenas das elites tradicionais, ou seja, não depende apenas do seu caráter arbitrário (extração da força física ou econômica), mas sim da aceitação implícita e dissimulada por parte da maioria da população. É o reconhecimento das práticas e do exercício destas como legítimas que as tornam eficazes. E, por 
fim, tentei apontar algumas implicações do modo de fazer política da família Gaudêncio e o modo como a própria busca se reinventar constantemente no intuito de continuar no poder local baseado na "sujeição do outrem", daqueles que vivem e sobrevivem da dependência dos dominantes, dos pertencentes à ortodoxia política local; portanto por meio desta prática política e de dependência demonstrei a perda da autonomia por partes dos agentes sociais e com isto a morte da alteridade, ou seja, destes que vivem e sobrevivem dos favores e da dependência por parte das lideranças locais.

Ao analisar as transformações do fazer político da família Gaudêncio, no contexto de mudanças estruturais importantes, foi possível perceber permanências e também criações de novas formas sociais, que se entrelaçam nas narrativas e elaborações dos próprios membros desta família. Da dissertação, é possível apreender um modo de perceber a história da família por seus próprios membros, e também perceber como refletem sobre o processo, como identificam dificuldades e como informam a posição familiar na política local e também em outras escalas de poder. A análise da família Gaudêncio permite recusar a visão de uma política imobilizada, presa ao passado, já que os próprios entrevistados narram transformações e os modos que elaboraram para compreendê-las. Mas essas mudanças só podem ser apreendidas no quadro das permanências e dos capitais acumulados.

\section{REFERÊNCIAS}

ALVES, Alessandro Cavassin. A província do Paraná e sua Assembleia Legislativa (1853- 1889): a força política das famílias tradicionais. Curitiba: Nova Letra, 2015.

BOURDIEU, Pierre. Sociologia. [org. Renato Ortiz; trad. de Paula Montero e Alicia Auzmendi]. São Paulo, Ática, 1983. . O poder simbólico, 4a ed. Rio de Janeiro; Bertrand Brasil, 2001.

Pierre. O Poder Simbólico. Tradução de Fernando Tomaz. $13^{\circ}$ ed. Rio de Janeiro: Bertrand Brasil, 2010.

BURSZTYN, Marcel. O poder dos donos: planejamento e clientelismo no Nordeste. 2 ed. Rio de Janeiro: Garamond: Fortaleza: BNB, 2008. 
CARVALHO, José Murilo de. Mandonismo, coronelismo, clientelismo: uma discussão conceitual. Dados, V.40, n.2 (1997), pp. 229-249.

FAORO, R. Os donos do poder: formação do patronato político brasileiro. Rio de Janeiro: Globo, 2004.

FORTUNATO, Maria Lucinete. O conceito de coronelismo e a imagem do coronel: de símbolo a simulacro do poder local. Campina Grande: EDUFCG, 2008.

GURJÃO, E. de Q. Morte e vida das oligarquias - Paraíba (1889-1945). 1. ed. João Pessoa: Editora Universitária/UFPB, 1994

HOUAISS, Antônio. Dicionário Houaiss da Língua Portuguesa. Rio de Janeiro, Ed. Objetiva, 2001

IBGE, Censo demográfico 2016. Disponível em: www.ibge.gov.br acesso em 17 de janeiro de 2016.

LEAL, Vitor Nunes. Coronelismo Enxada e Voto: o município e o regime representativo no Brasil. 3으 ed. São Paulo: ed. Nova Fronteira; 1997.

LEWIN, Linda. Política de parentela na Paraíba: um estudo de caso da oligarquia de base familiar. Trad. André Villalobos. Rio de Janeiro: Record, 1993.

MAIA, Kaliane de Freitas. O "Agronegócio sertanejo". (Re) pecuarização e grande propriedade rural na microrregião de Catolé do Rocha (PB, Semiárido Nordestino. 2013. 219f. Tese (Doutorado em Ciências Sociais) - PPGCS, Universidade Federal de Campina Grande, Campina Grande. 2013.

MARIZ, Celso. Evolução Econômica da Paraíba. 2oed. João Pessoa: A União, 1978.

MEDEIROS, Tarcízio Dinoá; MEDEIROS, Martinho Dinoá. Ramificações genealógicas do Cariri paraibano. Brasília: CEGRAF, 1989.

MONTEIRO, José Marciano. Família, poder local e dominação: um estudo sobre os processos de disputas políticas entre a(s) família (s) Ernesto- Rêgo em Queimadas/Paraíba. Dissertação de Mestrado, PPGCS: Campina Grande, 2009. (168p.) 
José Marciano. A política como negócio de família: os herdeiros e a força dos capitais no jogo político das elites na Paraíba (1985-2015). Campina Grande - PB, 2016. 289 f., il. color. Tese (Doutorado em Ciências Sociais) - Universidade Federal de Campina Grande, Centro de Humanidades, 2016.

MOREIRA, Márcio Macêdo. Entre Britos e Gaudêncios: cultura política e poder familiar nos Cariris velhos da Paraíba (1930- 1960). João Pessoa, 2012. 221f. : il. Dissertação (Mestrado) UFPB/CCHLA.

MOREIRA, E.; TARGINO, I. De Território de Exploração a Território de Esperança: Organização Agrária e Resistência Camponesa no Semi-árido Paraibano. Revista NERA, ano 17710, n.10, 2007.

Universitária/ UFPB, 1997.

Capítulos de Geografia Agrária da Paraíba. João Pessoa: Editora

OLIVEIRA, F. de. Elegia para uma re(li)gião: SUDENE, Nordeste, planejamentos e conflito de classes. 2. ed. Rio de Janeiro: Paz e Terra, 1981. 137p.

OLIVEIRA, Roberto Cardoso. "O Trabalho do Antropólogo: Olhar, Ouvir e Escrever". In: O trabalho do Antropólogo. 2a edição. Brasília, Paralelo 15, São Paulo, Editora UNESP, 2000. (p. 17 a 37)

RIBEIRO, Marlene. Movimento Camponês, trabalho e educação: liberdade, autonomia, emancipação: princípios/fins da formação humana. São Paulo: Expressão Popular, 2010.

TAVARES, J. de L. Apontamentos para a história territorial da Parahyba. Edição Facsimilar. Coleção Mossoroense, 1982.

TRIGUEIRO, Oswaldo. A Paraíba na primeira República. João Pessoa: A UNIÃO, 1982.

VILAÇA, Marcos Vinícius, ALBUQUERQUE, Roberto Cavalcante. Coronel, Coronéis, 2.ed. Rio de Janeiro: Tempo Brasileiro; Brasília: Ed. Universidade de Brasília, 1978.

VILLA, Marco Antonio. Vida e morte no sertão: A história das secas no século XIX e XX. São Paulo: Ática, 2003. 
WEBER, Max. A Política como Vocação. In: Ensaios de Sociologia - Rio de Janeiro: Zahar Editores, 2013. 